\title{
Effect of degassed elements on the degradation behavior of carbon nanotube cathodes in sealed field emission-backlight units
}

\author{
Sora Lee ${ }^{\mathrm{a})}$ and Duk Young Jeon \\ Department of Materials Science and Engineering, Korea Advanced Institute of Science and Technology, \\ 373-1, Guseong-dong, Yuseong-gu, Daejeon 305-701, Republic of Korea
}

(Received 11 October 2005; accepted 1 January 2006; published online 6 February 2006)

\begin{abstract}
The effect of degassed elements from the phosphor layer on a carbon nanotube (CNT) cathode was investigated. During the operation of field emission backlight units, it was found that zinc and sulfur were degassed from the phosphor anode. X-ray photoelectron spectroscopy analysis showed that $s p^{2}$ bonding in the CNTs changed to zinc-assisted $s p^{3}$-like bonding, modified by the adsorption of the zinc. The change of the CNT structure to a nonhexagonal carbon network suggests that the electron emission from the degraded CNT tips decreases due to the higher work function of $s p^{3}$-like bonding, compared to that of $s p^{2}$ bonding. (C) 2006 American Institute of Physics. [DOI: 10.1063/1.2167791]
\end{abstract}

Due to their large electric-field enhancement resulting from their high aspect ratio and due to their low operating voltage, carbon nanotubes (CNTs) are very useful materials for vacuum electronic applications, such as field emission (FE) displays, and backlight units (BLUs) for liquid crystal displays. One of the key issues for the industrial viability of CNT FE-BLUs is degradation of their cathodes. ${ }^{1-3}$ The recent report concerning CNT field emitters by Bonard et al. ${ }^{3}$ has shown that failures during $\mathrm{FE}$ occur at or near the substrate-emitter contact. Their findings showed that degradation of CNT tips is due to a mechanical failure of the contact at low applied fields, and also due to resistive heating at a high emitted current. Additionally, Dean et al. ${ }^{4}$ have shown that adsorbates on the surface of CNTs induce the current saturation at high applied fields since they desorb due to resistive heating. Based upon these reports, several possible explanations of the degradation behavior on a microscopic level can be given. Among them are the decrease in the height of the nanotubes, the disruption of electronic states in the cap, and the interaction between the CNT and a chemical element. $^{3-6}$

However, other factors, which could also induce the degradation, cannot be ruled out. In actuality, the operation of CNT tips occurs in a sealed panel fabricated with a packaging process, such that in most devices the CNT tips are not operating as a single nanotube but instead as a group, with variations such as defects, adhesion variations, and contact resistance. Moreover, the pressure inside the device packaged with a phosphor anode increases during the operation of the device, as degassed elements are instantly generated as a result of electron bombardment. As well, they cannot escape from the device. ${ }^{12,13}$ It is well known that the degassed elements such as $\mathrm{O}_{2}, \mathrm{H}_{2} \mathrm{O}, \mathrm{H}_{2}$, and others can affect the surface of CNT tips through a chemical interaction with them, assisted by the resistive heating of the CNT tip and also by ion bombardment. ${ }^{4,6,7}$ However, there is an absence of reports concerning the effects of metal elements degassed from the phosphor anode to the CNT tips. Therefore, to clarify the process of degradation of the CNT cathode by the phosphor anode, it is necessary to understand the identity of degassed elements that are induced from the cathode and anode of the

\footnotetext{
${ }^{a)}$ Electronic mail: soralee@kaist.ac.kr
}

panel. It is also important to understand their effects on the FE of the cathode in an actual sealed panel with a phosphor anode. In this letter, we describe the types of elements degassed from the phosphor anode and report their effects on the CNT cathode degradation in a sealed panel.

The cathode of FE-BLU panel was prepared by the screen-printing method. The CNT paste consisted of a commercial MWCNT (Il Jin Nanotech. Co., Korea), an organic binder and an inorganic binder. The CNT paste was premixed for 10 min using an agate mortar. Following that, three-roll milling was carried out to facilitate further mixing and dispersion of CNT powder in the binder. The prepared CNT paste was printed on silver-coated soda lime glass. On the anode part, a phosphor layer was screenprinted onto an indium tin oxide glass. The phosphors used in the anode consisted of $\mathrm{ZnS}: \mathrm{Ag}, \mathrm{Cl}$ for blue emission, $\mathrm{ZnS}: \mathrm{Cu}, \mathrm{Al}$ for green emission, and $\mathrm{Y}_{2} \mathrm{O}_{3}: \mathrm{Eu}^{3+}$ for red emission.

FE-BLU panels were prepared utilizing a packaging process in a vacuum environment of $10^{-5}-10^{-6}$ Torr. The sealed panels were driven at a constant voltage mode of $4 \mathrm{~V} / \mu \mathrm{m}$

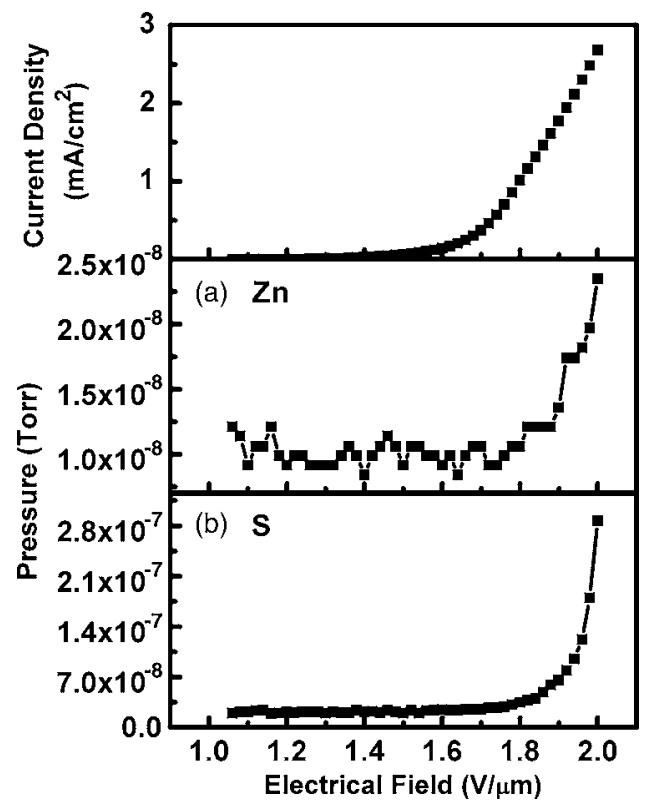

FIG. 1. Variation of amount of degassed (a) zinc, and (b) sulfur during the electron emission by applied electrical field. 
for a range of time durations. The driving duration of the samples was $0 \mathrm{~min}$ for the reference panel, $10 \mathrm{~min}$ for the lightly degraded panel, and $8 \mathrm{~h}$ for the heavily degraded panel. The measured current density of all three panels was $2.8 \mathrm{~mA} / \mathrm{cm}^{2}$ at $2 \mathrm{~V} / \mu \mathrm{m}$ in the early state. After the driving of the panels, samples for performing wavelength dispersive spectroscopy (WDS) and x-ray photoelectron spectroscopy (XPS) were prepared from the samples. Residual gas analysis (RGA) was performed in order to detect types of residual gases present in the panels and to measure their amounts.

From the RGA results, it was found that $\mathrm{Zn}$ and $\mathrm{S}$ were degassed from the phosphors during the operation of the panel. Figure 1 shows the relative variation between the amounts of electrons emitted by the applied electrical field and the degassed elements $\mathrm{Zn}$ and S, respectively. From Fig. 1 , we found that degassing of $\mathrm{Zn}, \mathrm{Y}$, and S starts when electrons are emitted by the applied electric field. Therefore, it was confirmed that the electron emission by the applied electrical field induced the degassing of $\mathrm{Zn}, \mathrm{Y}$, and $\mathrm{S}$ from the phosphor layer. The amount of degassed $\mathrm{Zn}$ and $\mathrm{S}$ is shown and compared in Figs. 1(a) and 1(b). The behavior of element $Y$ was similar to that of S. From the result of RGA, it was found that $\mathrm{S}$ was degassed by an amount ten times greater than was $\mathrm{Zn}$. However, it is unclear whether $\mathrm{S}$ is the primary element affecting the CNT tips.

To determine which element among $\mathrm{Zn}, \mathrm{Y}$, and S affects the CNT surface or structure, WDS (EPMA 1600, Shimadzu Co.) analysis was performed on the surface of the CNT cathode. From the result of WDS analysis, only Zn was detected. The relative amount of $\mathrm{Zn}$ on the surface of degraded CNT was close to $0.4 \%$, in contradistinction to a standard $\mathrm{Zn}$ source of WDS equipment. Despite the relatively large
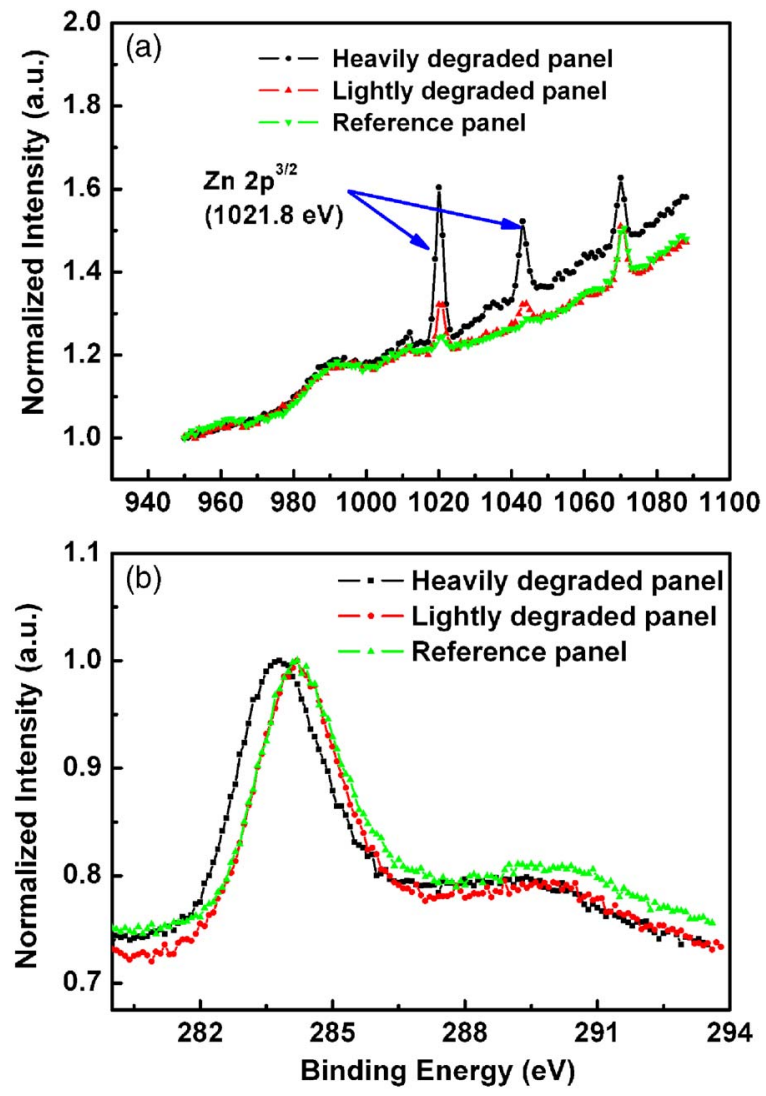

FIG. 2. (Color online) XPS spectra of (a) zinc adsorbed on the surface of

CNT, and (b) C $1 s$ core level of three panels.
Downloaded 18 Apr 2011 to 143.248 .103 .56 . Redistribution subject to AIP license or copyright; see http://apl.aip.org/about/rights_and_permissions
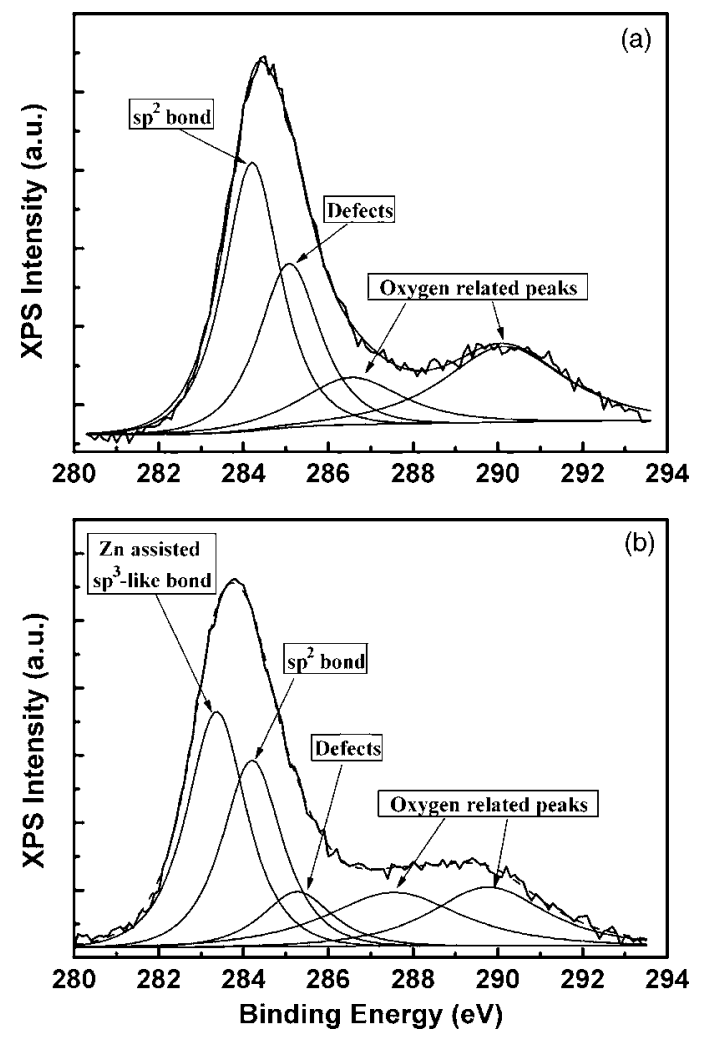

FIG. 3. XPS spectra of deconvoluted C $1 s$ core-level peak of (a) reference panel, and (b) heavily degraded panel.

amount of $\mathrm{S}$ and $\mathrm{Y}$ degassed from the phosphor anode, it is worth noting that $\mathrm{S}$ and $\mathrm{Y}$ do not interact with the CNT tips but only $\mathrm{Zn}$ interacts with these elements.

Degassed Zn can be adsorbed on the surface of the CNT tips in various ways. Two examples are: (1) A chemically adsorbed state, or (2) a physically adsorbed state. The influence of $\mathrm{Zn}$ on the CNT cathode was investigated by XPS analysis. The results are shown in Figs. 2 and 3. In the full scan spectra [Fig. 2(a)], two peaks of $\mathrm{Zn} 2 p^{3 / 2}$ and $2 p^{1 / 2}$ appeared in the data for both the heavily and lightly degraded panels. In addition, changes in the carbon bonding, caused by the adsorbed $\mathrm{Zn}$ were observed from the $1 \mathrm{~s}$ core-level spectra of $\mathrm{C}$. This also meant that the hexagonal CNT structure was altered. The $1 s$ core-level spectra of $\mathrm{C}$ showed asymmetric line shapes exhibiting a tailing toward higher binding energy. ${ }^{9,11}$ The degradation of the CNT cathode shifted the $\mathrm{C} 1 s$ core-level peak position from $284.2 \mathrm{eV}$ to a lower binding energy region, as shown in Fig. 2(b). To analyze the cause of the peak shift, the spectrum of $\mathrm{C} 1 s$ was fitted with four components, as shown in Fig. 3. As can be seen in Fig. 3(a), the CNT cathode fabricated by the screenprinting method has a $s p^{2}$ hybridized carbon bond of $284.2 \mathrm{eV}$ and defects. On the other hand, Fig. 3(b) shows that the intensity of the peak $(284.2 \mathrm{eV})$ related to the $s p^{2}$ hybridized bond was reduced in the case of the heavily degraded panel, and a new peak appeared at $283 \mathrm{eV}$. It was considered that the peak at the position of $283 \mathrm{eV}$ is a $\mathrm{Zn}$ assisted $s p^{3}$-like bond. The $\mathrm{ZnC}_{2}$ alloy and some XPS results concerning the bonding between the carbon and metal elements such as $\mathrm{Ge}$ were reported. ${ }^{10,12}$ The $\mathrm{C}-\mathrm{Ge}$ bond has appeared at about $283.4 \mathrm{eV}$ in Vilcarromero et al. ${ }^{9}$ Therefore, it was likely that the $\mathrm{Zn}$ adsorbed on the surface of the CNT tips reacted chemically with the CNT and changed the license or copyright; see http://apl.aip.org/about/rights_and_permissions 

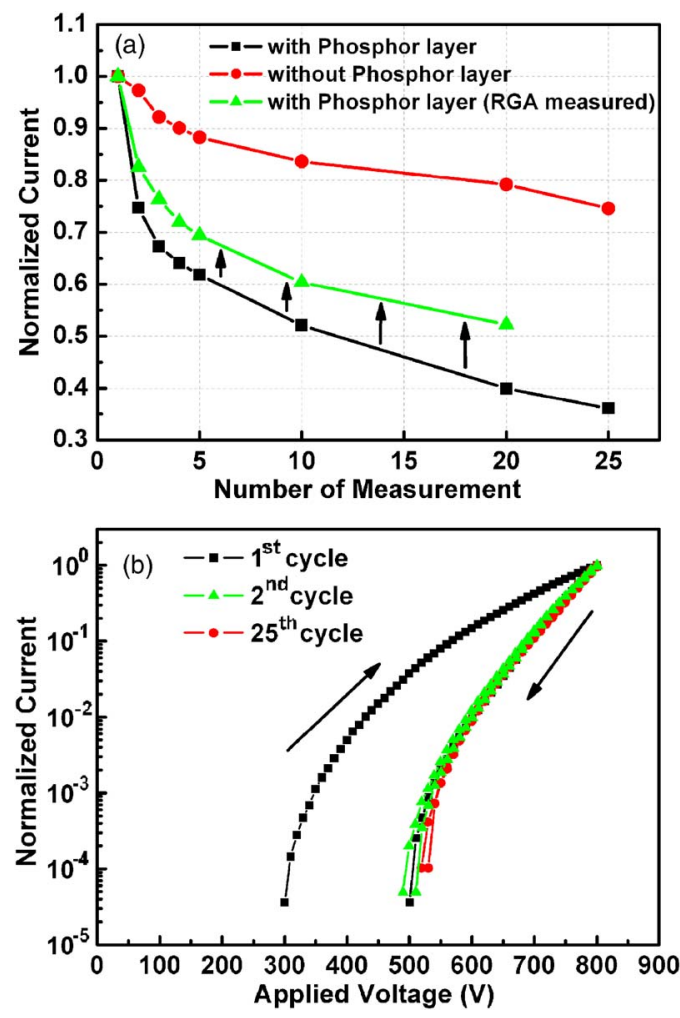

FIG. 4. (Color online) (a) Degradation behavior of various sealed panels by the number of measurement, and (b) hysteresis during the multiple FE cycling.

$s p^{2}$-hybridized bond structure of the CNT to a $\mathrm{Zn}$-assisted $s p^{3}$-like bond. Finally, the CNT tips had the mixture state with a $s p^{2}$ bond and a $\mathrm{Zn}$ assisted $s p^{3}$-like bond.

To determine the degradation phenomenon by the adsorption of $\mathrm{Zn}$ in the sealed panel during the operation, 25 repetition cycles were performed with the applied voltage range between 100-800 V. From these multiple field emission cycles, hysteresis was observed. This is shown in Fig. 4. Figure 4(a) shows that the current level decreased during the operation of the panel, and that the panel without the phosphor layer (-0-) showed a better performance than one with a phosphor layer (--). In Fig. 4(a), a small increase in the current curve of the RGA measured panel (- $\mathbf{\Delta}-)$ was due to the partial removal of degassed elements, including $\mathrm{Zn}$ and S. According to prior research concerning the field emission of diamondlike carbon (DLC) film, it was reported that the increase of the $s p^{3} / s p^{2}$ ratio in the DLC film induces the decrease of the FE property. Since the work function of a $s p^{3}$ bond is higher than that of a $s p^{2}$ bond, the work function of DLC film is increased by the increase of the $s p^{3} / s p^{2}$ ratio and the FE property is thus decreased. ${ }^{13}$ Consequently, this study was concerned with the possibility that the degassed $\mathrm{Zn}$ from the phosphor anode induced the degradation of the CNT tips by the change of the bonding state and the increase of the work function on the surface of the CNT.

Figure 4(b) shows the hysteresis of the sealed panel during the repeated cycling operation. Hysteresis was found only on the occasion of the first cycle. This finding was similar to that of other panels, one example being the panel without the phosphor, and another the RGA measured panel. The hysteresis found in the first cycle of the FE was in agreement with the current saturation behavior. ${ }^{4}$ However, according to our results from the RGA, the adsorbate is not re- moved completely from the surface of the CNT by the one cycle in the early state. We observed that the adsorbates, such as $\mathrm{H}_{2}, \mathrm{CO}$, and $\mathrm{O}_{2}$, were degassed continuously from the panel even though hysteresis was not found after the first cycle. Only the decrease of the current level was observed.

On the basis of these various cited reports and of our observations, we consider the degradation behavior of the CNT tips during operation divided into two categories of operation hysteresis. The first is the degradation by various factors during the first operation, and the second is degradation after the first operation. During the first driving, the degradation-which is the current saturation as reported by Bonard and Dean ${ }^{3}$ - occurred as witnessed by the mechanical failure of the CNT tips. After the first driving, the degradation occurred by means of a chemical interaction between the CNT tips and the metal elements in the inner space of the panel. A mechanical failure of CNT tips can also occur after a first driving; however, that type of failure may not be considered as serious as current saturation with a current decrease. We hold that the decrease of the current level after the first driving can be explained by the chemical interaction with $\mathrm{Zn}$ and the mechanical failure in the CNT tips. Additionally, it is possible that other elements such as $\mathrm{Al}, \mathrm{Fe}$, and Co may induce a chemical interaction with the CNT tips.

In conclusion, the effect of elements degassed from the phosphor anode on the CNT cathode was evaluated using sealed FE-BLU panels. From the results of RGA, WDS, and XPS in the inner space of the CNT cathode tips in the panels, it is found that the CNT cathode in the sealed panel was degraded due to chemically adsorbed $\mathrm{Zn}$ degassed from the phosphor anode. The change of the CNT structure to a nonhexagonal carbon network suggests that the electron emission from the degraded CNT tips decreases by the high work function of the $\mathrm{Zn}$-assisted $s p^{3}$-like bonding. Consequently, it is suggested that an effective way to prevent degradation of CNT is to change phosphors to a non-Zn-based system, or to reduce the degassing of $\mathrm{Zn}$ from the phosphor. Additionally, the chemical interaction between the CNT tips and other metal elements must be monitored.

The authors would like to thank Epion Co. for their effort about the panel packaging during this research work.

${ }^{1}$ S. K. Kang, J. H. Choi, J. H. Park, J.-H. Han, J.-B. Yoo, J.-W. Nam, C. K. Lee, and J. M. Kim, J. Vac. Sci. Technol. B 22, 1345 (2004).

${ }^{2}$ J.-M. Bonard, J.-P. Salvetat, T. Stöckli, W. A. de Heer, L. Forró, and A. Châtelain, Appl. Phys. Lett. 73, 918 (1998).

${ }^{3}$ J.-M. Bonard, C. Klinke, K. A. Dean, and B. F. Coll, Phys. Rev. B 67, 115406 (2003).

${ }^{4}$ K. A. Dean and B. R. Chalamala, Appl. Phys. Lett. 76, 375 (2000).

${ }^{5}$ L. Nilsson, O. Groening, P. Groening, and L. Schlapbach, Appl. Phys. Lett. 79, 1036 (2001).

${ }^{6}$ D.-H. Kim, H.-S. Yang, H.-D. Kang, and H.-R. Lee, Chem. Phys. Lett. 368, 439 (2003).

${ }^{7}$ K. A. Dean and B. R. Chalamala, Appl. Phys. Lett. 75, 3017 (1999).

${ }^{8}$ W. Yi, T. J. Jeong, S. Yu, J. Heo, C. Lee, J. Lee, W. Kim, J.-B. Yoo, and J. Kim, Adv. Mater. (Weinheim, Ger.) 14, 1464 (2002).

${ }^{9}$ H. E.-Szwarckopf, Carbon 42, 1713 (2004).

${ }^{10}$ J. Vilcarromero and F. C. Marques, Appl. Phys. A: Mater. Sci. Process. 70, 581 (2000).

${ }^{11}$ S. D. Gardner, C. S. K. Singamsetty, G. L. Booth, G.-R. He, and C. U. Pittman, Jr., Carbon 33, 587 (1995).

${ }^{12}$ A. A. Shulzhenko, I. Yu. Ignatyeva, A. S. Osipov, and T. I. Smirnova, Diamond Relat. Mater. 9, 129 (2000).

${ }^{13}$ H.-S. Jung, H.-H. Park, S. S. Pang, and S. Y. Lee, Thin Solid Films 355, 151 (1999). 